\title{
PERBUATAN HUKUM SANKSI ADAT PENYAMIL DI DESA PAKRAMANTANGGAHAN PEKEN, DESA SULAHAN, KECAMATAN SUSUT, KABUPATEN BANGLI
}

Oleh:

Ni Made Radha Rani Devi

I Made Suta

Institut Hindu Dharma Negeri Denpasar

\begin{abstract}
Bali Customary Law is a law or regulation written with unwritten conditions that contain commands and prohibitions for the behavior of indigenous peoples in matters governed by human relations with God, human relations with the environment, and human relations with humans, which in Bali is known as dialogue Tri Hita Karana. The imposition of traditional sanctions is a way to restore balance or neutralize the shock caused by traditional violations that have taken place in the Pakraman village environment. Such as the imposition of the Penyamil Customary Sanction which was handed down because the community committed acts that violated the existing provisions in Desa Pakraman Tanggahan Peken.

Based on this, the issues discussed in this study include: What legal actions can be imposed by the Penyamil Customary Sanction in Pakraman Tanggahan Peken Village, Sulahan Village, Susut District, Bangli Regency?

The problems that arise are examined using the theory of validity and effectiveness of the law in dissecting the formulation of problems regarding legal actions that can be subject to Penyamil Customary Sanctions in the Village of Pakraman Tanggahan Peken, Sulahan Village, Susut District, Bangli Regency. Data collection in this study used interview techniques, literature study techniques, questionnaire distribution and observation. In this study, the type of research used is a type of empirical legal research.

Penyamil Customary Penalty Occurrence in Desa Pakraman Tanggahan Peken due to harsh/ dirty words and misbehavior in a holy place or in a village meeting, and because of this error a person who is violated is subject to Penyamil Customary Sanction which can be in the form of financial penalties or Maprayascita fines, depending on the mistakes made. The factors that influence the occurrence of violations of the Penyamil Customary Sanction due to community ignorance, emotional, and developments in the current era of globalization.
\end{abstract}

Keywords: Actions, Customary Sanctions, Penyamil

\section{PENDAHULUAN}

Indonesia merupakan Negara Hukum, yang merupakan Norma atau peraturan tertulis maupun tidak tertulis yang dibuat oleh banan-badan resmi. Selain Hukum Nasional Indonesia mengenal adanya Hukum Adat, yang merupakan hukum asli dari bangsa Indonesia, yang sebagian besar peraturan hukum adat tidak tertulis, namun hukum itu tetap tumbuh dan berkembang serta dipertahankan dengan kesadaran dari masyarakat. Peraturan adat merupakan suatu kebiasaan dari masyarakat yang mempunyai peraturan-peraturan yang tidak dikitabkan, namun peraturan yang tertulis bersumber dari adat istiadat dari bangsa Indonesia yang berlaku bagi seluruh warga masyarakat. 
Hukum Adat Bali merupakan hukum atau peraturan yang tertulis maupun tidak tertulis yang berisi perintah dan larangan untuk mengatur tingkah laku dari masyarakat adat dalam hal menjaga hubungan manusia dengan Tuhan, hubungan manusia dengan lingkungan dan hubungan manusia dengan manusia,yang dibali dikenal denagn ajaran Tri Hita Karana.

Peraturan Daerah Provinsi Bali No. 3 Tahun 2003 tentang Desa Adat, yang mengganti istilah "Desa Pakraman" menjadi "Desa Adat". Desa Pakraman adalah kesatuan masyarakat Hukum Adat berdasarkan filosofi Tri Hita Karana yang berakar dari kearifan lokal Sad Kertih, dengan dijiwai ajaran agama hindu dan nilai-nilai budaya serta kearifan lokal yang hidup di Bali, sangat besar peranannya dalam pembangunan masyarakat, bangsa, dan Negara sehingga perlu diayomi, dilindungi, dibina, dikembangkan, serta diberdayakan guna mewujudkan kehidupan Krama Bali yang berdaulat secara politik, berdikari secara ekonomi, dan berkepribadian dalam kebudayaan.

Setiap Desa Pakraman harus tetap berpedoman dan tunduk kepada aturan Hukum Nasional yang berlaku di Indonesia. Fungsi dari Awig-awig adalah sebagai pengatur hak dan kewajiban yang harus ditaati oleh seluruh warga desa tanpa terkecuali, dan Awig-awig ada bukan untuk menakut-nakuti warga desanya namun, apabila Awig-awig itu dilanggar maka dapat dikenakan sanksi sesuai dengan berat ringannya kesalahan yang telah dilakukan, dan untuk menyangga stabilitas sosial dalam suatu Desa Pakraman.

Penjatuhan Sanksi Adat merupakan cara untuk mengembalikan keseimbangan atau menetralisir kegoncangan karena pelanggaran adat yang terjadi di lingkungan Desa Pakraman. Seperti penjatuhan terhadap Sanksi Adat Penyamil yang di jatuhkan karena masyarakat melakukan perbuatan yang melanggara ketentuan yang ada Di Desa Pakraman Tanggahan Peken.

Perbuatan melawan hukum merupakan perbuatan yang bertentangan dengan aturan hukum yang berlaku. Seperti dalam Hukum Nasional mengenai perbuatan melawan hukum yang termuat dalam pasal 1365, pasal 1366 dan pasal 1367 Kitab Undang-undang Hukum Perdata.

Terdapat 4 (empat) unsur dari perbuatan melawan hukum yaitu: 1 . Perbuatan itu harus melawan hukum, 2. Perbuatan itu harus menimbulkan kerugian, 3. Pernuatan itu harus dilakukan dengan kesalahan, 4. Perbuatan itu harus ada hubungan kausal sebab akibat

Desa Pakraman Tanggahan Peken merupakan suatu Desa Pakraman yang hanya mempunyai 1 (satu) Desa Pakraman Adat, yang mana biasanya dalam suatu Desa Pakraman terdiri dari beberapa Desa Pakraman adat. Desa Pakraman Tanggahan Peken terdapat suatu kasus mengenai pelanggaran adat yang di lakukan oleh warga Desa Pakraman, yang mengucapkan katakata yang tidak pantas (kasar) dan karena perbuatannya itu, dalam rapat desa (Paruman) dapat dijatuhkan Sanksi Penyamil.

Pelanggaran yang pernah terjadi di Desa Pakraman Tanggahan Peken yaitu mengatakan betapa senangnya menjadi seka gong baru megambel satu kali datang wedang (kopi) megambel dua kali dapat ajengan (nasi) dan yang akhinya terjadi ketersinggungan yang akhirnya melaporkan ke Prajuru Desa dan dilakukan sebuah paruman yang akhirnya menjatuhkan Sanksi Penyamil berupa dikenakan banten maprayascita di Pura Dalem Nyambu. Dan juga dijatuhkan Sanksi Penyamil karena mengucapkan "Betek nyantung betek nyantung", mengucapkan "nyalang basang kelian gong", dan meminta timbaline sesunan, karena tidak mendapat ijin langsung mengucapkan "jek mulih abe engken neh ".

Sanksi Penyamil memiliki arti yang sama dengan Sanksi Pecamil yaitu sanksi yang dikenakan kepada seorang yang mengucapkan kata-kata kotor, kasar, dan dengan maksud mempengaruhi pejabat atau petugas. Perbuatan ini dapat menimbulkan keresahan karena dianggap menodai kesucian tempat tersebut, seperti pura, pasar, Desa Pakraman dan desa. Oleh karena itu sanksi yang dikenakan sesuai dengan akibat yang ditimbulkan. 
Berdasarkan latar belakang diatas maka permasalahan yang akan dibahas adalah mengenai Perbuatan Hukum Yang Dikenakan Sanksi Adat Penyamil di Desa Pakraman Tanggahan Peken, Desa Sulahan, Kecamatan Susut, kabupaten Bangli.

\section{METODE PENELITIAN}

Penelitian ini berlokasi di Desa Pakraman Tanggahan Peken, Desa Sulahan, Kecamatan Susut, Kabupaten Bangli. Desa Pakraman Tanggahan Peken merupakan desa yang menerapkan sanksi adat karena berbicara yang tidak pantas yang dari pelanggaran tersebut dikenakan Sanksi Adat Penyamil.

Jenis penelitian ini adalah penelitian kualitatif. Pada umumnya penggunaan jenis penelitian kualitatifbertujuan untuk menguraikan, menggambarkan serta menceritakan secara sistematis fakta dan karakteristik subjek atau objek yang diteliti secara tepat.

Penelitian ini bersifat deskriptif, penlitian deskriptif adalah penelitian yang mendeskripsikan suatu gejala, peristiwa, kejadian yang terjadi saat ini. Penelitian deskriptif memusatkan perhatian terhadap masalah-masalah actual sebagaimana yang terjadi pada saat penelitian itu berlangsung. Bentuk dan sumber data terdiri dari data primer, data yang diperoleh atau dikumpulkan di lapangan oleh peneliti. Penelitian primer adalah hasil dari wawancara terhadap informan, yaitu prajuru dan masyarakat. Data Sekunder, biasanya diperoleh dari perpustakaan atau dari laporan-laporan yang terdahulu (Iqbal,2002:82).

Pengumpulan data menggunakan teknik observasi, teknik wawancara, teknik studi kepustakaan, dan teknik quisioner. Penentuan informan penelitian menggunakan teknik purposive sampling, instrument penelitian atau alat penelitian adalah penelitian itu sendiri sehingga peneliti harus "divalidasi". Adapun alat yang yang digunakan untuk menunjang penelitian ini, maka peneliti menggunakan handphone, buku yang digunakan untuk mencatat pertanyaan dan poin-poin dari hasil wawancara. Pengolahan dan analisis data yaitu deskriptif dan komporatif.

\section{HASIL PENELITIAN}

\section{Pengertian Sanksi Adat Penyamil}

Sanksi adat dijatuhkan sesuai dengan besar kecil, berat ringannya kesalahan yang telah dilakukan oleh masyarakat, seperti Sanksi Adat Penyamil yang ada dan diterapkan Di Desa Pakraman Tanggahan Peken. Sanksi Penyamil adalah Sanksi Adat yang terbilang ringan, yang dijatuhkan karena pelanggaran berhubungan dengan kepentingan pribadi yaitu dikenakan kepada masyarakat yang mengucapkan perkataan yang kasar, kotor, dan lain-lain.

Kata Penyamil diambil dari kata dasar Camil yang yang mendapat awalan "Pe" dan sisipan "ny" sehingga di Desa Pakraman Tanggahan Peken disebut dengan Sanksi Penyamil. Kata Camil memiliki arti yang mirip dengan kata Comel hanya saja comel merupakan suka atau gemar berkata-kata, suka bergunjing atau suka ngobrol atau banyak mulut. Sedangkan Camil adalah Comel yang bernilai negatif berkata yang kotor-kotor, memaki, keras, menyakiti hati dan sebagainya. Dalam Bahasa Bali Camil sama artinya dengan "ngomong tan pakletu". (Kaler,1983:26)

2. Perbuatan yang dapat dikenakan Sanksi Adat Penyamil

Pengertian perbuatan dalam Kamus Besar Bahasa Indonesia merupakan suatu yang diperbuat (dilakukan), tindakan, dan dapat diartikan sebagai tingkah laku. Mengenai perbuatan melawan hukum diperkuat dengan adanya aturan dalam hukum nasional yaitu dalam pasal 1365 Kitab Undang-Undang Hukum Perdata yang berbunyi: "tiap perbuatan yang melanggar hukum dan membawa kerugian kepada orang lain, mewajibkan orang menimbulkan kerugian itu karena kesalahannya untuk menggantikan kerugian tersebut". (Soimin, 2010: 336)

Menurut I Ketut Bawa, yang dapat dikenakan Sanksi Penyamil adalah dapat dijatuhkan kepada warga yang berkata-kata kasar, kotor, menghina dan lain sebagainya, hanya saja Sanksi Penyamil hanya dijatuhkan karena salah ucap atau berbicara yang kasar.(Wawancara, 28 April 2019) 
I Wayan Sutisna berpendapat bahwa yang dapat dikenakan Sanksi Penyamil adalah masyarakat salah ucap atau berkata kasar, kencing di areal pura, mengambil hasil panen orang lain, membuang sampah keselokan dan lain sebagainya. (Wawancara, 28 April 2019)

Berdasarkan dari hasil wawancara diatas dapat dijelaskan bahwa Sanksi Penyamil yang ada dan diterapkan di lingkungan Desa Pakraman Tanggahan Peken, dapat dijatuhkan karena pelanggaran atau perbuatan dari oknum masyarakat yang dianggap melakukan kesalahan karena berbicara bahkan bertingkah laku yang tidak atau kurang baik.

3. Faktor Yang Mempengaruhi Terjadinya Pelanggaran Adat Penyamil

Penyebab dari perbuatan itu mungkin dikarenakan berbagai faktor, sehingga dalam menjatuhkan pamidanda atau Sanksi Adat harus melalui Paruman terlebih dahulu. Harapan dan tujuan dari dijatuhkannya sanksi atau pamidanda oleh Desa Pakraman dapat memberikan efek jera dan agar masyarakat yang ada di lingkungan Desa Pakraman Tanggahan Peken dapat berfikir terlebih dahulu sebelum mengucapkan atau berkata-kata kepada orang lain.

Adapun faktor yang mempengaruhi diterapkannya Sanksi Adat Penyamil yang karena salah ucap berdasarkan hasil wawancara menurut I Wayan Sinar adalah:

1) Faktor individu itu sendiri merupakan Faktor kejiwaan individu itu sendiri dapat menyebabkan kejahatan seperti daya emosional, rendahnya mental, sakit hati dengan korban, dan dendam.

2) Faktor ketidaktahuan masyarakat juga merupakan penyebab terjadinya tindak kejahatan ujaran kebencian (hate speech) khususnya penghinaan yang dilakukan masyarakat. Kurangnya sosialisasi/penyuluhan kepada masyarakat inilah yang menyebabkan kejahatan ini terjadi di masyarakat yang tergolong tidak tahu akan adanya aturan mengenai kejahatan ujaran kebencian khususnya penghinaan.
3) Faktor sarana dan fasilitas juga berpengaruh pada era globalisasi seperti saat sekarang ini, dan itu juga berpengaruh pada tumbuh pesatnya media elektronik khususnya media internet sehingga penyebaran informasi semakin mudah, cepat dan efektif untuk didapatkan. Sehingga seseorang kurang bijaknya menggunakan sarana media internet ataupun komunikasi serta tidak ada batasan dalam penggunaan alat komunikasi. (Wawancara,4 Juni 2019)

Menurut I Wayan Suardana, Sanksi Penyamil yang ada di tanggahan peken dikenakan karena berbicara yang tidak baik, yang mana disebabkan karena ketidaksengajaan (keceplosan) berbicara pada saat piodalan di Pura. Dari Kesalahan tersebut dikenakan banten maprayascita di Pura tersebut.

4. Akibat Hukum Dijatuhkannya Sanksi Adat Penyamil

Akibat hukum adalah suatu akibat yang ditimbulkan oleh hukum, terhadap suatu perbuatan yang dilakukan oleh subjek hukum (Ahmad Ali, 2008:192). Akibat hukum merupakan suatu akibat dari tindakan yang dilakukan, untuk memperoleh suatu akibat yang diharapkan oleh pelaku hukum. Akibat yang dimaksud adalah akibat yang diatur oleh hukum, sedangkan tindakan yang dilakukan merupakan tindakan hukum yaitu tindakan yang sesuai dengan hukum yang berlaku. (Soeroso, 2006:295)

Penjatuhan sanksi terhadap pelaku pelanggaran adat, terkadang dapat menimbulkan suatu akibat, baik pribadi maupun akibat yang lebih luas yaitu berdampak terhadap masyarakat, meskipun hukuman yang telah dijatuhkan telah dijalankan dan tidak terdapat permasalahan dalam menjalankan sanksi adat tersebut namun dalam kehidupan bermasyarakat terkadang orang yang telah atau pernah dikenakan sanksi atau hukuman akan menjadi bahan pembicaraan oleh masyarakat sekitar bahkan terkadang dijauhi. Sanksi Adat Penyamil yang ada di Desa Pakraman Tangggahan Peken merupakan sanksi yang termasuk ke dalam Delik Adat yang berhubungan dengan kepentingan pribadi. 
Setiap sanksi yang sudah dijatuhkan kepada yang melakukan pelanggaran adat pastilah ada danda, yang dari masing-masing danda yang di dapat oleh pelanggar tergantung dari seberapa besar kesalahan yang telah diperbuat. Begitupun perbuatan karena salah ucap di Desa Pakraman Tanggahan Peken sudah tentu akan mendapat danda berupa Danda Uang dan danda yang berupa sajen atau banten yaitu:

1) Danda uang merupakan danda yang dalam Hukum Hindu dikenal dengan arta danda yang mana denda yang akan di peroleh dari kesalahannya yaitu denda yang dapat berupa uang ataupun barang yang dapat berupa beras dll.

2) Danda sajen atau banten merupakan denda yang dikenal dalam Sangaskara Danda yaitu tindakan hukuman untuk mengembalikan keseimbangan magis (hukuman dalam bentuk melakukan upacara agama).

Pemberian atau penjatuhan suatu Denda tergantung dari kesalahan yang telah diperbuat. setiap sanksi dan denda yang diberikan kepada masyarakan yang melanggar hanya untuk menumbuhkan perasaan yang aman, kedaimaian dan adil kepada seluruh masyarakat.

Selain itu, dari perbuatan akibat berbicara yang tidak baik/kasar dan kotor terkadang akan memberikan dampak dari akibat salah ucap tersebut cendrung diterima oleh orang yang melakukan pelanggaran adat itu sendiri. Dampak yang mengarah kepada Psikologis orang tersebut karena perasaan malu, penyesalan dan canggung bila bertemu dengan masyarakat yang lain. Hal ini dapat ditimbulkan karena meskipun masyarakat menerima dengan hadirnya ditengah-tengah masyarakat karena dianggap sudah melaksanakan dan menjalankan kewajiban terhadap adat, namun pada saat ada masyarakat yang membicarakan mengenai pelanggaran itu juga dapat berdampak kepada orang yang pernah melakukannya.

\section{SIMPULAN DAN SARAN}

1) Simpulan

Perbuatan hukum yang dapat dikenakan

Sanki Adat Penyamil Di Desa Pakraman Tanggahan Peken yaitu suatu pelanggaran yang berkaitan dengan delik adat tentang kepentingan pribadi, yang dikenakan kepada masyarakat karena mengucapkan kata-kata kotor, memfitnah, menipu dan berbohong. Faktor yang mempengaruhi adanya Sanksi Adat Penyamil adalah faktor indvidu, faktor ketidaktahuan masyarakat, dan faktor sarana dan fasilitas yang berpengaruh pada era globalisasi saat ini. Akibat hukum dijatuhkan Sanksi Adat Penyamil yaitu dapat memberikan efek jera kepada orang yang melakukan pelanggaran dan memberikan contoh kepada masyarakat yang lain agar tdak mengulangi atau melakukan kesalahan yang sama.

\section{2) Saran}

Setiap Sanksi Adat yang di terapkan dan dijalankan di Desa Pakraman hendaknya hasil dari paruman tersebut dicatatkan, kerena dari pada pencatatan tersebut dapat menjadi bukti otentik dan dapat dijadikan pedoman jika nantinya ada masyarakat yang melakukan kesalahan yang sama. Suatu Aturan yang ada perlunya dilakukan sosialisasi agar terdapat pemahaman mengenai aturan yang ada di Desa Pakraman tersebut.

Hendaknya Pararem yang dilakukan melalui Paruman Adat di buat secara tertulis mengenai kesalahan dan sanksi yang akan dikenakan, karena agar tidak terjadi ketidak adilan apabila orang yang melakukan kesalahan tersebut adalah orang yang dianggap penting dalam desa tersebut jadi sanksi yang di kenakan lebih ringan dan orang atau masyarakat biasa melakukan kesalahan sanksi yang dikenakan lebih besar. Maka dari itu Sanksi Adat yang akan dikenakan haruslah dibuatkan pencatatan agar tidak terjadi tumpang tindih di lingkungan Desa Pakraman tersebut, agar terciptanya rasa keadilan dan ketentraman bagi seluruh masyarakat.

\section{DAFTAR PUSTAKA}

Ahmad Ali, 2008, Menguak Tabir Hukum, Jakarta, Ghalia Indonesia.

Iqbal, Hasan. 2002. Pokok-Pokok Metodelogi Penelitian Dan Aplikasi. Indonesia. halia

Kaler, I.G.K. 1983. Butir-butir Tercecer tentang Adat Bali. (Jilid 1dan2). Denpasar : Bali Agung.

Peraturan Daerah Provinsi Bali Nomor 3 Tahun 2003

Soimin, Soedharyo. 2010. Kitab Undang-Undang Hukum Perdata. Jakarta: Sinar Grafika

Soeroso, R. 2006. Praktik Hukum Acara Perdata. Jakarta: Sinar Grafika 